\title{
EFFECT OF SODIUM 2,3-DIMERCAPTOPROPANE-1-SULPHONATE (DMPS) ON CHRONIC DAUNORUBICIN TOXICITY IN RABBITS: COMPARISON WITH DEXRAZOXANE
}

\author{
Radomír Hrdina ${ }^{1}$, Vladimír Geršl ${ }^{2}$, Ivona Klimtová ${ }^{1}$, Tomáš Šimůnek ${ }^{1}$, Yvona Mazurová ${ }^{3}$, \\ Jarmila Macháčková ${ }^{2}$ Michaela Adamcová ${ }^{4}$
}

Charles University in Prague, Faculty of Pharmacy in Hradec Králové: Department of Pharmacology and Toxicology ${ }^{1}$; Charles University in Prague, Faculty of Medicine in Hradec Králové: Department of Pharmacology ${ }^{2}$, Department of Histology and Embryology ${ }^{3}$, Department of Physiology ${ }^{4}$

Summary: A possible protective action of DMPS (a dithiol chelating agent) against chronic daunorubicin toxicity in rabbits in comparison with dexrazoxane was investigated. The rabbits were divided into five groups: control (saline, $1 \mathrm{ml} / \mathrm{kg}$ i.v.), daunorubicin ( $3 \mathrm{mg} / \mathrm{kg}$ i.v.), DMPS ( $50 \mathrm{mg} / \mathrm{kg}$ i.v.); the remaining two groups were pre-treated either with dexrazoxane $(60 \mathrm{mg} / \mathrm{kg}$ i.p.) or DMPS ( $50 \mathrm{mg} / \mathrm{kg}$ i.v.) $30 \mathrm{~min}$ before administration of daunorubicin $(3 \mathrm{mg} / \mathrm{kg}$ i.v.). Drugs were given once a week for 10 weeks. Routine biochemical parameters were determined in weeks 1,5 and 11 . In the $11^{\text {th }}$ week, invasive haemodynamic parameters were measured, then the rabbits underwent autopsy, cardiac tissue was examined by light microscopy and scored semiquantitatively. The contents of calcium, potassium, magnesium, iron and selenium were measured in the left heart ventricle. DMPS administered alone was well tolerated and did not cause any major signs of toxicity. It decreased the cardiac content of calcium, but did not affect the iron concentration. In contrast to dexrazoxane, DMPS pre-treatment did not prevent the decline in body weight in weeks 8-11 caused by daunorubicin, actually worsened mortality (26.7\% vs $40.0 \%$ ), did not ameliorate daunorubicin-induced nephrotic syndrome, and did not prevent the occurrence of the severe myocardial lesions. Unlike dexrazoxane, a lack of protective effect of DMPS against chronic daunorubicin toxicity in rabbits was demonstrated. The underlying cause may consist in the fact that DMPS does not efficiently chelate tissue iron and thus may not prevent the formation of oxygen free radicals.

Key words: 2,3-dimercaptopropane-1-sulphonate; Daunorubicin; dexrazoxane; Cardiotoxicity; Nephrotoxicity; Rabbit

\section{Introduction}

Anthracycline antibiotics are among the most effective and widely used antineoplastic agents. Their clinical usefulness is, however, largely limited by a cumulative dose-related cardiotoxicity and other non-cardiac toxicities (25). The precise mechanisms of anthracycline cardiotoxicity have not been elucidated as yet. It is believed that cardiotoxic and possibly other cytotoxic actions of anthracyclines are caused, at least partly, by production of oxygen free radicals (39). This has been experimentally demonstrated both in vitro $(13,27)$ and in vivo (29). Apart from other approaches to mitigate anthracycline cardiotoxicity (e.g. modification of the dosage schedule) (43), a number of cardioprotectants have been tested with equivocal results. Dexrazoxane (ICRF-187), a bisdioxopiperazine compound originally developed as an antitumour agent (8), is the only clinically approved drug for the prevention of anthracycline cardiotoxicity (44). The protective effect appears to be due to either removal of iron from anthracycline-iron complexes and/or binding of free iron in cardiomyocytes. Thus the catalytic role of iron in generation of oxygen free radicals is diminished $(14,34,44)$. Dexrazoxane is usually reported not to affect anthracyclines antitumour activity and not to increase the incidence of non-cardiac toxicities $(28,15,45)$. In women with advanced breast cancer, however, dexrazoxane decreased the response rate to combined antitumour treatment as compared with the placebo group (48\% vs $63 \%$, resp.) (2). In higher doses (> 600-750 mg/m² i.v.), dexrazoxane may increase bone marrow depression (20,45). These facts encourage further investigation of potential cardioprotectants with lower toxicity.

Sodium 2,3-dimercaptopropane-1-sulphonate (DMPS), a dithiol orally active chelating agent with low toxicity (11), may hypothetically chelate iron (22), and due to two - SH groups it may act as an antioxidant (4). Thus, DMPS may not only scavenge oxygen free radicals, but it may also prevent their formation. In this study the authors tested a pos- 
sible protective action of DMPS against chronic daunorubicin toxicities, primarily against cardiotoxicity, in rabbits. The action of DMPS was compared with that of a reference agent - dexrazoxane.

\section{Material and methods}

Animals. Medium size Chinchilla male rabbits (weight range $2.80-3.30 \mathrm{~kg}$ at the beginning of the experiment) were used. The experiments complied with the "European Convention for the Protection of Vertebrate Animals Used for Experimental and other Scientific Purposes" (1) and were under the supervision of the Ethical Committee of the Faculty of Medicine in Hradec Králové.

Origin of drugs and chemicals. Daunorubicin (Cérubidine, Laboratoires Roger Bellon, France), 2,3-dimercaptopropane-1-sulphonic acid, sodium salt (Sigma Chemie, Czech Republic), dexrazoxane (Cardioxane, Eurocetus, Netherlands), sodium pentobarbitone (Nembutal Sodium, Abbott, USA), heparin (Heparin inj., Léčiva, Czech Republic), aqua pro inj. (Biotika, Slovakia), saline (Solutio natrii chlorati isotonica, Biotika, Slovakia)

Experimental design. A total number of 57 rabbits was divided into five groups: 1 . control $\left(\mathrm{n}_{1}=15\right.$, saline $1 \mathrm{ml} / \mathrm{kg}$ i.v.); 2. daunorubicin $\left(\mathrm{n}_{2}=15,3 \mathrm{mg} / \mathrm{kg}\right.$ i.v.); 3. DMPS $\left(\mathrm{n}_{3}=12,50 \mathrm{mg} / \mathrm{kg}\right.$ i.v. $) ; 4$. dexrazoxane + daunorubicin $\left(\mathrm{n}_{4}=5,60 \mathrm{mg} / \mathrm{kg}\right.$ i.p. $+3 \mathrm{mg} / \mathrm{kg}$ i.v., $30 \mathrm{~min}$ interval); 5. DMPS + daunorubicin $\left(\mathrm{n}_{5}=10,50 \mathrm{mg} / \mathrm{kg}\right.$ i.v. $+3 \mathrm{mg} / \mathrm{kg}$ i.v., $30 \mathrm{~min}$ interval). Drugs or their combinations were given once a week for 10 weeks. Blood samples were withdrawn at least after $12 \mathrm{hr}$ fasting in weeks 1 (initial value), 5 and 11 (final value), and biochemical parameters were determined. At the end of the experiment, invasive haemodynamic variables were measured in anaesthetized animals. Then the rabbits were killed by an overdose with pentobarbitone, the thorax and abdomen were opened and examined for the presence of transudate. The heart was taken for histological examination. A sample of the left ventricle was removed to determine the content of selected elements. All animals, which died during the study, also underwent autopsy; histological examination was performed only in those animals where autopsy followed immediately after premature death.

Biochemical parameters measurement. The following biochemical parameters were determined in plasma/serum using a Hitachi 717 analyser (Japan): sodium, potassium, calcium, chloride, magnesium, phosphate, glucose, urea, creatinine, uric acid, bilirubin, lactate dehydrogenase (LD), alanine aminotransferase (ALT), aspartate aminotransferase (AST), creatine kinase (CK), alkaline phosphatase (ALP), cholesterol, triglycerides, proteins incl. electrophoresis.

Invasive heamodynamic measurement. At the end of the experiment the rabbits were anaesthetized with sodium pentobarbitone $(25 \mathrm{mg} / \mathrm{kg}$ i.v.). Polyethylene catheters $(1.6 / 2.4 \mathrm{~mm}$; filled with heparinized saline, $10 \mathrm{IU} / \mathrm{ml})$ were introduced into the right femoral artery and through the left carotid artery into the left cardiac ventricle, respectively. The catheters were connected to Gold Statham P 23 ID pressure transducers (USA). The mean arterial blood pressure, left ventricular pressure, and left ventricular differential pressure $\left(\mathrm{dP} / \mathrm{dt}_{\max }\right)$ were recorded following a $15 \mathrm{~min}$ equilibrium period after an instrumentation with the use of a polygraph Biomedica C6b (Italy) and a differentiator (VÚFB Prague, Czech Republic).

Histological examination. Tissue blocks of transversally sectioned heart ventricles (the region under the atria) were fixed by immersion in $10 \%$ buffered formalin. Paraffin sections $(7 \mu \mathrm{m})$ were regularly stained with Masson's blue trichrome. A 5-point scale of morphological changes was applied for light microscopic semiquantitative evaluation of myocardial lesions (12).

Myocardial elements content assay. Calcium, potassium, magnesium, iron and selenium content were measured in samples of the dried myocardial tissue after microwave digestion with nitric acid and hydrogen peroxide. Calcium, magnesium, and selenium were determined by atomic absorption spectrophotometry using an Unicam Sollar analyser 959 (USA). Potassium and iron were measured photometrically using an Eppendorf Efox 5053 (Germany) and Hitachi 717 (Japan), respectively.

Statistical analysis. The data are expressed as the mean \pm SEM for $n$ observations. The homogeneity of variances between groups was tested by F test and the appropriate unpaired t-test was used for the following comparisons: daunorubicin and DMPS groups were compared to the control group; "treated" groups (i.e. dexrazoxane + daunorubicin and DMPS + daunorubicin) were compared with the daunorubicin group. Changes in data within groups (i.e. the $5^{\text {th }}$ and $11^{\text {th }}$ weeks in comparison with the $1^{\text {st }}$ week) were tested by the paired t-test. A $\chi^{2}$ test was used to determine the significance of differences in the severity of cardiomyopathy scores between groups. $\mathrm{P}<0.05$ was used as the level of statistical significance.

\section{Results}

General toxicity. Treatment with DMPS did not prevent a decline in body weight caused by daunorubicin administration starting in week 9 (Fig. 1). Mortality encountered in the daunorubicin group achieved $26.7 \%$, DMPS co-administration actually worsened it to $40.0 \%$. In contrast, no mortality was observed in rabbits pre-treated with dexrazoxane. Growth curve displayed nearly the same shape as in the control group.

Biochemical parameters. Important changes in biochemical parameters are summarized in Table 1. These changes, characteristic for the nephrotic syndrome induced by daunorubicin, were partly reduced by dexrazoxane, but not by DMPS co-administration. Other measured parameters either did not show any consistent changes or the changes were difficult to interpret (e.g. changes in CK activity were affected by repeated i.m. injections). 
Invasive haemodynamic measurement. Daunorubicin significantly depressed left ventricular contractility indicated by a decrease in $\mathrm{dP} / \mathrm{dt}_{\max }$ (Table 2). DMPS itself did not change this parameter. Pre-treatment with both dexrazoxane and DMPS tended to attenuate depressive effect of daunorubicin. None of the treatment regimens changed significantly the mean blood pressure.

Postmortem examination. Marked signs of congestion - ascites, pleural effusion and hydropericardium - were observed in $26.7 \%$ of rabbits treated with daunorubicin and in

Tab. 1: Important changes of biochemical parameters during the experiment.

\begin{tabular}{|c|c|c|c|c|c|c|}
\hline Parameter & Week & $\begin{array}{l}\text { Control } \\
\left(n_{1}=15\right)\end{array}$ & $\begin{array}{c}\text { Daunorubicin } \\
\left(\mathrm{n}_{2}=15\right)\end{array}$ & $\begin{array}{l}\text { DMPS } \\
\left(n_{3}=12\right)\end{array}$ & $\begin{array}{c}\text { Dexrazoxane+ } \\
\text { daunorubicin } \\
\left(\mathrm{n}_{4}=5\right)\end{array}$ & $\begin{array}{c}\text { DMPS + } \\
\text { daunorubicin } \\
\left(\mathrm{n}_{5}=10\right)\end{array}$ \\
\hline \multirow{3}{*}{$\begin{array}{c}\text { urea } \\
(\mathrm{mmol} / \mathrm{l})\end{array}$} & 1 & $7.9 \pm 0.3$ & $7.4 \pm 0.5$ & $9.7 \pm 0.3^{c}$ & $7.1 \pm 0.5$ & $6.5 \pm 0.8$ \\
\hline & 5 & $8.6 \pm 0.4$ & $7.5 \pm 0.5$ & $9.1 \pm 0.3$ & $6.3 \pm 0.5$ & $7.5 \pm 0.5$ \\
\hline & 11 & $7.8 \pm 0.3$ & $12.3 \pm 2.0^{* \mathrm{c}}$ & $8.8 \pm 0.7$ & $6.7 \pm 0.3^{\mathrm{d}}$ & $13.0 \pm 1.7^{*}$ \\
\hline \multirow{3}{*}{$\begin{array}{l}\text { creatinine } \\
(\mu \mathrm{mol} / 1)\end{array}$} & 1 & $91.2 \pm 4.1$ & $90.1 \pm 6.6$ & $90.9 \pm 1.9$ & $87.4 \pm 6.5$ & $90.0 \pm 3.7$ \\
\hline & 5 & $96.3 \pm 2.8^{*}$ & $94.8 \pm 5.6$ & $97.0 \pm 3.7$ & $79.0 \pm 2.5^{\mathrm{d}}$ & $96.8 \pm 3.9^{*}$ \\
\hline & 11 & $97.4 \pm 4.1$ & $176.1 \pm 27.5^{* \mathrm{c}}$ & $100.0 \pm 5.3$ & $78.8 \pm 4.8^{\mathrm{d}}$ & $171.8 \pm 21.2^{*}$ \\
\hline \multirow{3}{*}{$\begin{array}{c}\text { cholesterol } \\
(\mathrm{mmol} / \mathrm{l})\end{array}$} & 1 & $1.0 \pm 0.1$ & $1.3 \pm 0.2$ & $1.2 \pm 0.1$ & $1.3 \pm 0.1$ & $1.5 \pm 0.1$ \\
\hline & 5 & $1.3 \pm 0.2$ & $1.3 \pm 0.2$ & $1.1 \pm 0.1$ & $1.1 \pm 0.1$ & $1.5 \pm 0.1$ \\
\hline & 11 & $0.8 \pm 0.1^{*}$ & $4.3 \pm 1.1^{* \mathrm{c}}$ & $3.2 \pm 2.5$ & $0.9 \pm 0.2^{\mathrm{d}}$ & $2.8 \pm 0.3^{*}$ \\
\hline \multirow{3}{*}{$\begin{array}{l}\text { triglycerides } \\
(\mathrm{mmol} / \mathrm{l})\end{array}$} & 1 & $1.0 \pm 0.1$ & $1.4 \pm 0.3$ & $0.9 \pm 0.1$ & $0.7 \pm 0.1^{\mathrm{d}}$ & $1.0 \pm 0.1$ \\
\hline & 5 & $0.9 \pm 0.1$ & $0.9 \pm 0.1$ & $1.1 \pm 0.1^{*}$ & $0.7 \pm 0.1$ & $0.7 \pm 0.1^{*} \mathrm{~d}$ \\
\hline & 11 & $1.3 \pm 0.1$ & $2.9 \pm 0.5^{* \mathrm{c}}$ & $1.2 \pm 0.1^{*}$ & $1.0 \pm 0.1^{\mathrm{d}}$ & $2.5 \pm 0.5^{*}$ \\
\hline \multirow{3}{*}{$\begin{array}{l}\text { protein } \\
(\mathrm{g} / 1)\end{array}$} & 1 & $62.3 \pm 1.1$ & $63.0 \pm 1.1$ & $64.7 \pm 0.8$ & $60.5 \pm 0.5$ & $62.6 \pm 1.0$ \\
\hline & 5 & $66.7 \pm 1.2^{*}$ & $62.0 \pm 0.7$ & $63.2 \pm 3.7$ & $62.5 \pm 0.9^{*}$ & $63.1 \pm 0.7$ \\
\hline & 11 & $62.0 \pm 1.5$ & $50.7 \pm 1.4^{* \mathrm{c}}$ & $64.9 \pm 1.7$ & $58.9 \pm 1.7^{\mathrm{d}}$ & $45.6 \pm 1.3^{\mathrm{d}}$ \\
\hline \multicolumn{7}{|l|}{$\begin{array}{c}\text { Electrophoresis } \\
(\%)\end{array}$} \\
\hline \multirow[t]{3}{*}{ albumin } & 1 & $66.3 \pm 1.0$ & $68.0 \pm 0.9$ & $69.8 \pm 1.3$ & $64.7 \pm 1.9$ & $68.8 \pm 1.0$ \\
\hline & 5 & $69.3 \pm 1.1^{*}$ & $67.8 \pm 0.6$ & $66.1 \pm 0.6^{*} \mathrm{c}$ & $70.7 \pm 0.8 d$ & $64.2 \pm 1.4^{*}$ \\
\hline & 11 & $66.7 \pm 1.7$ & $54.7 \pm 2.7 * \mathrm{c}$ & $66.7 \pm 0.9$ & $67.5 \pm 1.0 \mathrm{~d}$ & $48.4 \pm 2.1^{*}$ \\
\hline \multirow[t]{3}{*}{$\alpha_{1}$-globulin } & 1 & $5.6 \pm 0.6$ & $5.7 \pm 0.7$ & $6.2 \pm 0.2$ & $7.6 \pm 0.4^{d}$ & $7.0 \pm 0.2$ \\
\hline & 5 & $5.7 \pm 0.4$ & $6.0 \pm 0.6$ & see note & $7.9 \pm 0.3$ & $7.1 \pm 0.4$ \\
\hline & 11 & $5.7 \pm 0.2$ & $10.1 \pm 0.8^{* \mathrm{c}}$ & $5.9 \pm 0.2$ & $6.7 \pm 0.3^{d}$ & $10.4 \pm 1.3^{*}$ \\
\hline \multirow[t]{3}{*}{$\alpha_{2}$-globulin } & 1 & $6.7 \pm 0.4$ & $5.8 \pm 0.2$ & $5.2 \pm 0.4^{\mathrm{c}}$ & $6.3 \pm 0.4$ & $6.0 \pm 0.2$ \\
\hline & 5 & $6.0 \pm 0.2$ & $6.2 \pm 0.2$ & $6.0 \pm 0.3^{c}$ & $5.9 \pm 0.5^{*}$ & $7.0 \pm 0.3^{* \mathrm{~d}}$ \\
\hline & 11 & $6.7 \pm 0.5$ & $8.3 \pm 0.5^{*} \mathrm{c}$ & $6.2 \pm 0.3^{*}$ & $5.7 \pm 0.3^{d}$ & $9.9 \pm 0.4^{* \mathrm{~d}}$ \\
\hline \multirow[t]{3}{*}{$\beta$-globulin } & 1 & $11.0 \pm 1.1$ & $9.8 \pm 0.8$ & $9.3 \pm 1.0$ & $9.4 \pm 0.6$ & $8.4 \pm 0.3$ \\
\hline & 5 & $10.6 \pm 0.9$ & $10.4 \pm 0.7$ & $15.6 \pm 0.4^{* \mathrm{c}}$ & $9.7 \pm 0.3$ & $9.5 \pm 0.3^{*}$ \\
\hline & 11 & $8.7 \pm 0.6$ & $11.4 \pm 0.7^{\mathrm{c}}$ & $8.2 \pm 0.3$ & $9.6 \pm 1.1$ & $13.9 \pm 1.4^{* \mathrm{~d}}$ \\
\hline \multirow{3}{*}{$\gamma$-globulin } & 1 & $12.5 \pm 0.9$ & $10.7 \pm 0.3$ & $10.6 \pm 0.5$ & $12.0 \pm 0.8$ & $9.8 \pm 0.7$ \\
\hline & 5 & $10.4 \pm 0.9$ & $9.7 \pm 0.7$ & $11.4 \pm 0.3$ & $5.8 \pm 1.1^{* \mathrm{~d}}$ & $12.2 \pm 0.9^{*} \mathrm{~d}$ \\
\hline & 11 & $12.7 \pm 1.3$ & $15.7 \pm 1.1^{*}$ & $11.5 \pm 0.7$ & $10.6 \pm 0.6^{\mathrm{d}}$ & $17.4 \pm 1.2^{*}$ \\
\hline
\end{tabular}

Note: values not measured due to interference between fractions of albumin and $\alpha_{1}$-globulin compared to: * - initial value, $\mathrm{c}$ - the control group, $\mathrm{d}-$ the daunorubicin group $(\mathrm{P}<0.05)$

Tab. 2: Parameters of the invasive haemodynamic measurement at the end of the experiment (week 11).

\begin{tabular}{|l|c|c|}
\hline Group & $\mathrm{dP} / \mathrm{dt}_{\max }(\mathrm{mmHg} / \mathrm{s})$ & Mean blood pressure $(\mathrm{mmHg})$ \\
\hline Control $\left(\mathrm{n}_{1}=15\right)$ & $9855 \pm 548$ & $94 \pm 2$ \\
\hline Daunorubicin $\left(\mathrm{n}_{2}=11\right)$ & $5565 \pm 803^{\mathrm{c}}$ & $86 \pm 5$ \\
\hline DMPS $\left(\mathrm{n}_{3}=12\right)$ & $10073 \pm 645$ & $98 \pm 3$ \\
\hline Dexrazoxane + daunorubicin $\left(\mathrm{n}_{4}=5\right)$ & $6975 \pm 548$ & $102 \pm 5$ \\
\hline DMPS + daunorubicin $\left(\mathrm{n}_{5}=6\right)$ & $6420 \pm 465$ & $87 \pm 4$ \\
\hline
\end{tabular}

c - compared to the control group $(P<0.05)$ 
$20.0 \%$ of animals pre-treated with DMPS. In other groups of rabbits no clear signs of congestion were visible.

Histopathology. The evaluation of myocardial damage is summarised in Table 3. The normal appearance of the myocardial tissue of control rabbits is shown in Fig. 2. Daunorubicin caused the disperse toxic damage of the rabbit myocardium followed by proliferation of fibrotic tissue as a reparative process (Fig. 3). The pre-treatment with dexrazoxane prevented the occurrence of this severe damage (Fig. 4) in comparison with DMPS pre-treatment, where the results were similar to or worse than the results in daunorubicin group (Fig. 5). DMPS itself did not cause any significant changes in the myocardium, i.e. the appearance of the heart tissue resembled the normal stage.

Myocardial content of elements. Daunorubicin caused a significant increase in the content of calcium and a significant decrease in potassium and magnesium concentration. Cardiac levels of iron and selenium were not significantly changed (Table 4). DMPS decreased calcium concentration by more than one third as compared to the controls, tended to decrease potassium and magnesium concentration. The concentration of iron and selenium was not significantly affected. Dexrazoxane pre-treatment prevented "calcium overload" induced by daunorubicin, other changes in cardiac elements concentration induced by daunorubicin were not significantly affected, though some tendency to a decrease in iron and selenium concentration was observed. DMPS co-administration also prevented an increase in calcium concentration induced by daunorubicin; levels of other elements were not practically changed by DMPS pre-treatment.

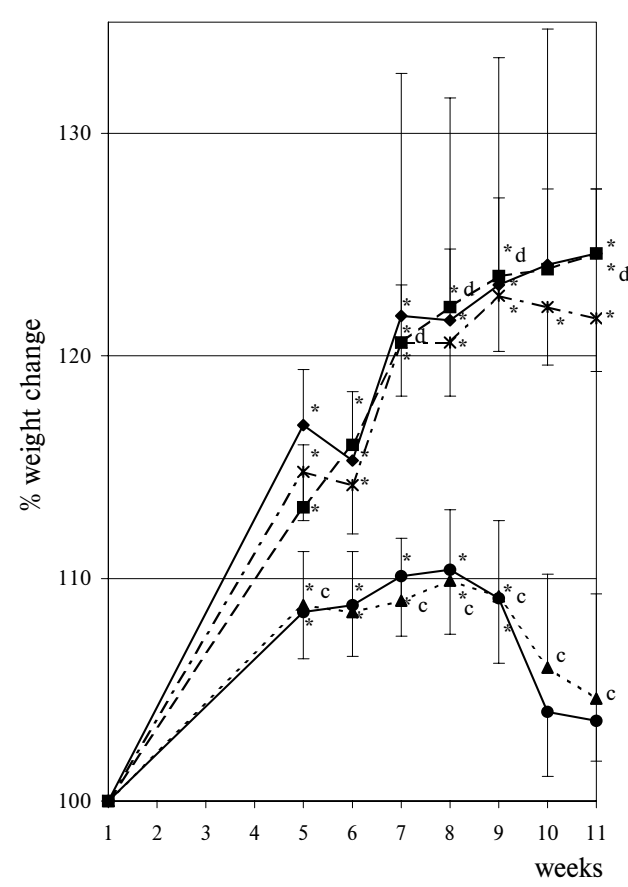

Fig. 1: Growth curves of rabbits throughout the experiment. Initial body weights $(\mathrm{kg})$ in tested groups were as follows: control $(\diamond) 3.1 \pm 0.1$, daunorubicin $(\Delta) 3.3 \pm 0.1$, DMPS $(\times) \quad 3.0 \pm 0.1$, dexrazoxane + daunorubicin $(\boldsymbol{\square}) 2.8$ \pm 0.1 , DMPS + daunorubicin $(\bullet) 2.8 \pm 0.1$. Statistical significance $(P<0.05)$ : * - compared with the initial value, c - compared to the control group, $d$ - compared to the daunorubicin group.

Tab. 3: Histological evaluation of the damage of myocardium scored according to the 5-point scale.

\begin{tabular}{|c|c|c|c|c|c|c|c|}
\hline & & \multicolumn{5}{|c|}{ Cardiomyopathy score } & \\
\hline Group & $\mathrm{n}$ & 0 & 1 & 2 & 3 & 4 & $P$ \\
\hline control & 15 & 8 & 7 & 0 & 0 & 0 & \\
\hline daunorubicin & 13 & 0 & 1 & 8 & 3 & 1 & $<0.05^{\mathrm{c}}$ \\
\hline DMPS & 12 & 0 & 12 & 0 & 0 & 0 & $\mathrm{NS}^{\mathrm{c}}$ \\
\hline dexrazoxane + daunorubicin & 5 & 0 & 3 & 2 & 0 & 0 & $\mathrm{NS}^{\mathrm{d}}$ \\
\hline DMPS + daunorubicin & 8 & 0 & 1 & 4 & 2 & 1 & $\mathrm{NS}^{\mathrm{d}}$ \\
\hline
\end{tabular}

NS - not significant; c - compared to the control group ( $\chi^{2}$ test $)$; $\mathrm{d}$ - compared to the daunorubicin group ( $\chi^{2}$ test)

Tab. 4: The content of selected elements in the left heart ventricle. Values are expressed in $\mu \mathrm{mol} / \mathrm{g}$ of dry tissue (selenium in $\mathrm{nmol} / \mathrm{g})$.

\begin{tabular}{|l|c|c|c|c|c|}
\hline Element & $\begin{array}{c}\text { Control } \\
\left(\mathrm{n}_{1}=15\right)\end{array}$ & $\begin{array}{c}\text { Daunorubicin } \\
\left(\mathrm{n}_{2}=13\right)\end{array}$ & $\begin{array}{c}\text { DMPS } \\
\left(\mathrm{n}_{3}=12\right)\end{array}$ & $\begin{array}{c}\text { Dexrazoxane }+ \\
\text { daunorubicin } \\
\left(\mathrm{n}_{4}=5\right)\end{array}$ & $\begin{array}{c}\text { DMPS }+ \\
\text { daunorubicin } \\
\left(\mathrm{n}_{5}=8\right)\end{array}$ \\
\hline Calcium & $9.3 \pm 1.0$ & $16.2 \pm 2.4^{\mathrm{c}}$ & $5.9 \pm 0.7^{\mathrm{c}}$ & $9.1 \pm 0.4^{\mathrm{d}}$ & $7.4 \pm 1.3^{\mathrm{d}}$ \\
\hline Potassium & $253.6 \pm 8.8$ & $225.3 \pm 5.0^{\mathrm{c}}$ & $226.6 \pm 17.1$ & $226.7 \pm 13.8$ & $213.3 \pm 12.2$ \\
\hline Magnesium & $33.7 \pm 1.5$ & $28.6 \pm 0.9^{\mathrm{c}}$ & $27.6 \pm 2.7$ & $29.7 \pm 0.9$ & $28.9 \pm 1.8$ \\
\hline Iron & $3.0 \pm 0.3$ & $2.8 \pm 0.2$ & $3.0 \pm 0.4$ & $2.5 \pm 0.1$ & $3.0 \pm 0.8$ \\
\hline Selenium & $6.7 \pm 1.7$ & $10.9 \pm 2.5$ & $8.5 \pm 1.0$ & $8.3 \pm 0.5$ & $10.4 \pm 1.1$ \\
\hline
\end{tabular}

c - compared to the control group $(P<0.05)$; d - compared to the daunorubicin group $(P<0.05)$ 


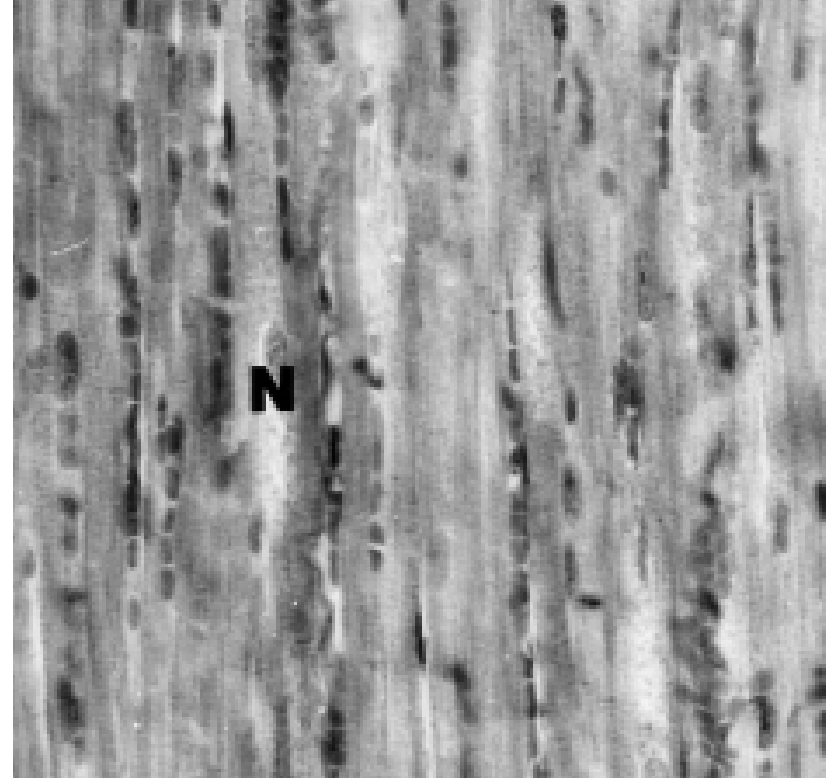

Fig. 2: Control group (score 0) - normal appearance of the myocardium; typical cross-striated myofibrils fill the cytoplasm of cardiomyocytes except the endoplasm (a pale-stained region) around the nucleus $(\mathrm{N})$; the capillaries (around each muscle fiber) are marked by chain of erythrocytes. Masson's blue trichrome, Mag. 1152x.

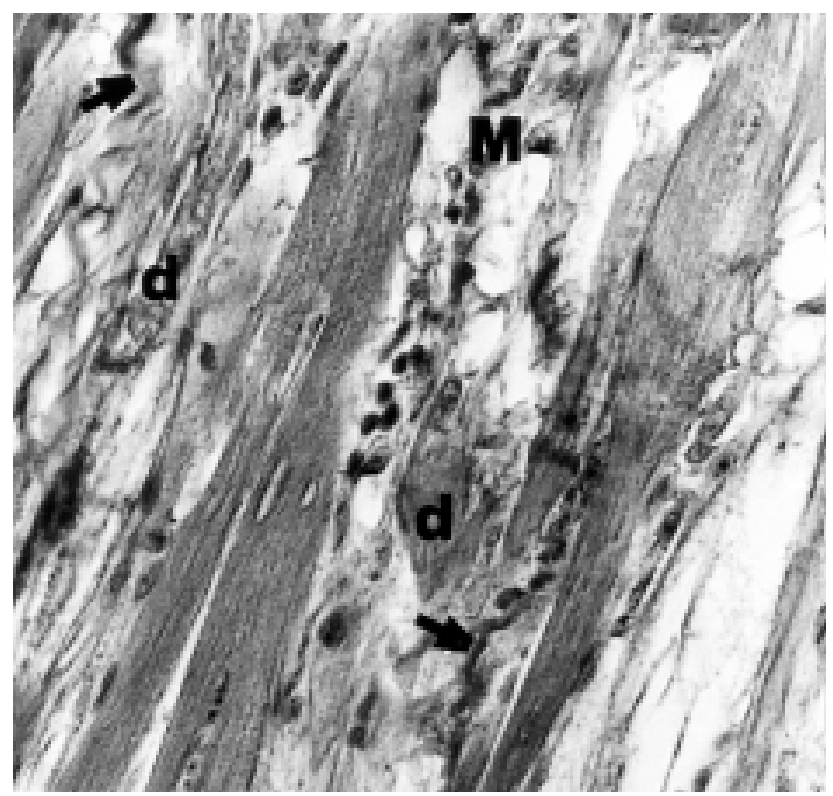

Fig. 3: Daunorubicin group (score 4) - numerous degenerated (d) or destroyed cardiomyocytes (white spaces) are gradually replaced by granulation tissue pointed up by conspicuous nuclei of macrophages (M) and scattered lymphocytes, and later by collagen fibers (arrows). Remaining, relatively undamaged myocytes in these foci possess mostly the intensely eosinophilic cytoplasm. Masson's blue trichrome, Mag. 1152x.

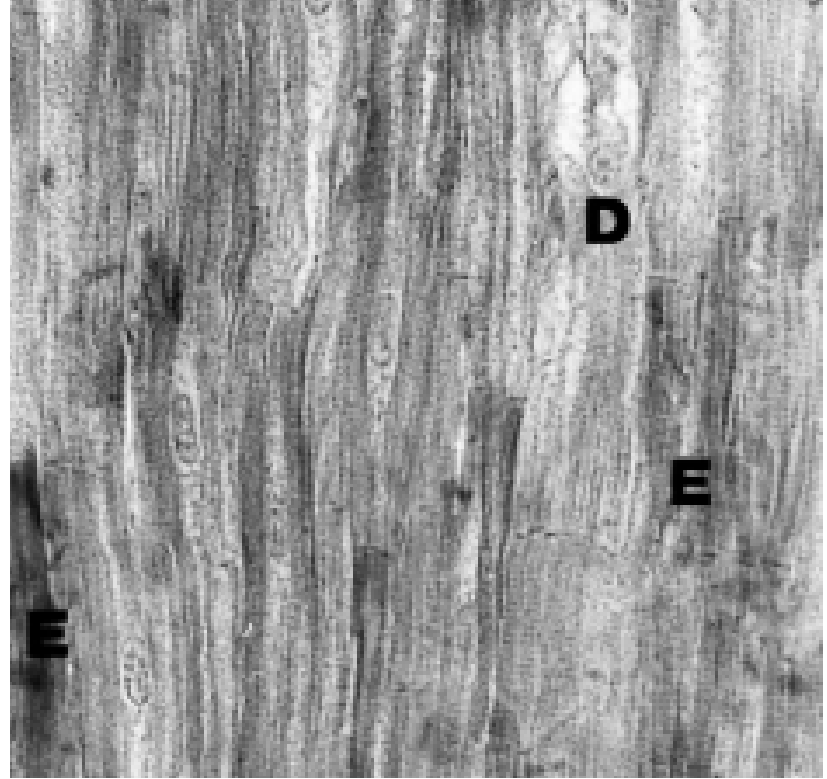

Fig. 4: Dexrazoxane-daunorubicin group (score 1) - large number (strips) of cardiomyocytes with intensely eosinophilic cytoplasm (darker stained - E) and scattered groups of degenerated/necrotic cells (D). Masson's blue trichrome, Mag. 1152x

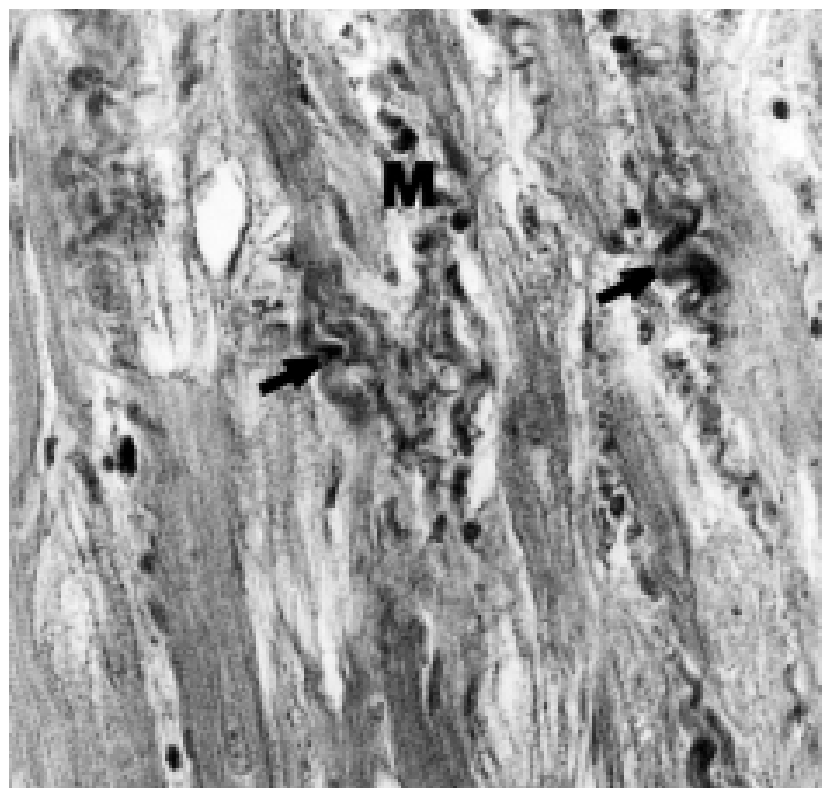

Fig. 5: DMPS-daunorubicin group (score 4) - degenerated (necrotic) cardiomyocytes (white spaces) are replaced by granulation tissue and macrophages $(\mathrm{M})$ - the healing process results in formation of the fibrotic scars marked by thick collagen fibers (arrows). There was no marked difference in microscopic picture of the myocardium damage in DMPS-daunorubicin and daunorubicin group. Masson's blue trichrome, Mag. 1152x. 


\section{Discussion}

Using the rabbit model of chronic anthracycline cardiotoxicity, which has been widely used in the studies of various protectants $(6,9,12,16,17,40,41)$, the present authors studied a possible protective action of DMPS against daunorubicin toxicity, especially cardiotoxicity. The selected dose of DMPS, i.e. $50 \mathrm{mg} / \mathrm{kg}$ i.v., is comparable (molar basis) with the usual dexrazoxane doses in fixed combinations with anthracyclines (weight ratio 20:1) (23).

General toxicity, postmortem examination. Daunorubicin caused a significant decrease in body weight, especially in the last three weeks of the experiment (Fig. 1). Unlike DMPS, dexrazoxane pre-treatment normalized the growth curve of rabbits. Similarly, mortality induced by daunorubicin $(26.7 \%)$ was prevented by dexrazoxane. This is consistent with the results of other experimental studies $(16,19)$. In contrast, DMPS co-administration actually worsened mortality induced by daunorubicin (40.0\%). Unlike DMPS, dexrazoxane prevented the occurrence of fluid accumulation in all pre-treated animals.

Biochemical parameters. The most marked changes in biochemical parameters demonstrated a nephrotoxic action of daunorubicin. Pathogenesis of anthracycline nephrotoxicity is not clear as yet. Most studies support a role of oxidative stress and lipid peroxidation (10,31,32,42); some authors, however, emphasize other mechanisms, e.g. interference with DNA metabolism (5). Partial protection against daunorubicin nephrotoxicity by dexrazoxane noted in the present study suggests a certain role of oxygen free radicals in its pathogenesis. In contrast, DMPS failed to prove any nephroprotective action. In blood, DMPS is rapidly oxidized to disulfide forms (30). In the kidney, disulfides may be reduced to the parent DMPS involving a glutathione (GSH)- disulfide exchange reaction (35). This may ensure the intracellular chelating activity of reduced DMPS, but at the expense of the GSH content and subsequent attenuation of antioxidant mechanisms involving GSH. Moreover, iron chelating activity of DMPS in renal tissue was not demonstrated in rats given DMPS in a cumulative dose 1.26 $\mathrm{g} / \mathrm{kg}$ i.p. during 3 week interval (38).

Invasive haemodynamic measurement. Chronic daunorubicin cardiomyopathy manifested by a significant decrease in $\mathrm{dP} / \mathrm{dt}_{\max }$ - a parameter of left ventricular contractility (26). DMPS alone did not change this parameter. Both dexrazoxane and DMPS pre-treatment partially non-significantly diminished a decrease in cardiac contractility induced by daunorubicin. Daunorubicin-induced decrease in cardiac contractility was not accompanied by a significant decrease in the mean blood pressure, possibly by a counteracting activation of vasoconstrictor mechanisms (3).

Histopathology. In compliance with some previous studies $(17,18,40)$ conspicuous differences in the extent and severity of the myocardial damage were found mainly between daunorubicin and dexrazoxane-daunorubicin groups. Though the differences between the pre-treated groups and the daunorubicin group were not statistically significant (Table 3), unlike DMPS, dexrazoxane prevented the severe myocardial damage. In comparison with the above-mentioned studies $(17,18,40)$, presence of many necrotic cells accompanied by mononuclear infiltrate (macrophages and scattered lymphocytes), and followed by proliferation of the fibrotic tissue were characteristics of daunorubicin-induced cardiomyopathy in our long-lasting (11 weeks) experiment.

Myocardial content of elements. A significant increase in myocardial calcium concentration (calcium overload) caused by daunorubicin observed in this study has been a welldocumented feature of anthracycline cardiotoxicity. This may result from the block of calcium-release channels in sarcoplasmic reticulum and subsequent accumulation of calcium (37), and from the inhibition of transport systems regulating calcium movement (33). Calcium overload induced by daunorubicin was prevented by pre-treatment with both dexrazoxane and DMPS. However, the underlying mechanisms of the preventive action seem to be different for individual drugs. By binding intracellular iron dexrazoxane decreases harmful cellular biochemical effects induced by anthracyclines, i.e. oxygen-derived free radicals production $(14,34,44)$, lipid peroxidation and subsequent damage of cellular membrane systems whose integrity is essential for cellular calcium homeostasis (46). Lesser extent of myofibrilar damage was seen also in this study as dexrazoxane prevented occurrence of the severe myocardial damage, i.e. stage 3 and 4 (necrosis of the cells) (Table 3, Fig. 4). In contrast, DMPS prevented calcium overload produced by daunorubicin possibly by direct chelation of calcium ions (Table 4). On the other hand, the present study did not prove any iron chelating action of DMPS, which was proposed hypothetically (22) and demonstrated in in vitro experiments (24). However, in in vivo studies, DMPS, used even in higher doses than in the present study, did not markedly change iron content in various tissues including the cardiac one $(36,38)$. A tendency to an increase in selenium concentration in daunorubicin group may possibly reflect an up-regulation of antioxidant enzyme gene expression and an increase in glutathione peroxidase (GSH-Px) activity in response to oxidative stress. This has been demonstrated in various models of anthracycline cardiotoxicity $(21,47)$. GSH-Px has been shown to serve as a major metabolic form of selenium against oxidative stress (7). Unlike DMPS, pre-treatment with dexrazoxane partially (non-significantly) attenuated an increase in selenium concentration. This may reflect partial reduction of oxidative stress induced by daunorubicin.

\section{Conclusions}

Data obtained in the present study suggest that DMPS does not appear to be an efficient iron chelator in vivo, and as the result, in a dose used in this study it did not demonstrate an effective action against daunorubicin toxicity in rabbits. 


\section{Acknowledgement}

The authors wish to thank Mrs L. Koželuhová for her technical assistance. This study was supported by a grant of GA CR 305/00/0365 and by a research project MSM 111600002.

\section{References}

1. Anonymous. "European Convention for the Protection of Vertebrate Animals Used for Experimental and other Scientific Purposes". Strasbourg, Council of Europe, 1986.

2. Anonymous. Dexrazoxane for cardiac protection against doxorubicin. Med Lett Drugs Ther 1995;37:110-1.

3. Arnolda L, McGrath B, Cocks M, Sumithran E, Johnston C. Adriamycin cardiomyopathy in the rabbit: an animal model of low output cardiac failure with activation of vasoconstrictor mechanisms. Cardiovasc Res 1985;19:378-82.

4. Benov LC, Ribarov SR, Monovich OH. Study of activated oxygen production by some thiols using chemiluminiscence. Gen Physiol Biophys 1992;11:195-202.

5. Bertolatus JA, Klinzman D, Bronsema DA, Ridnour L, Oberley LW. Evaluation of the role of reactive oxygen species in doxorubicin hydrochloride nephrosis. J Lab Clin Med 1991;118:435-45.

6. Bocherens-Gadient SA, Quast U, Nussberger J, Brunner HR, Hof RP. Chronic adriamycin treatment and its effect on the cardiac $\beta$-adrenergic system in the rabbit. J Cardiovasc Pharmacol 1992;19:770-8.

7. Cheng WH, Ho YS, Valentine BA, Ross DA, Combs Jr. GF, Lei XG. Cellular glutathione peroxidase is the mediator of body selenium to protect against paraquat lethality in transgenic mice. J Nutr 1998;128:1070-6.

8. Creighton AM, Hellmann K, Whitecross S. Antitumour activity in a series of bisdiketopiperazines. Nature 1969;222:384-5.

9. Dimitrov NV, Hay MB, Siew S, Hudler DA, Charamella LJ, Ullrey DE. Abrogation of adriamycin-induced cardiotoxicity by selenium in rabbits. Am J Pathol 1987;126:376-83.

10. Dioudis C, Grekas D, Papageorgiou G et al. Lipid peroxidation and antioxidan defence mechanisms in rat renal tissue after daunorubicin administration. Ren Fail 1996;18:537-43.

11. Domingo JL. Embryotoxic and teratogenic effects of chelating agents used in the prevention and treatment of metal intoxications. Rev Toxicol 1995;12:56-64.

12. Geršl V, Cerman J, Šuba P, Mazurová Y, Hrdina R, Macháčková J. IGF-I in experimental daunorubicin-induced cardiomyopathy in rabbits. Hum Exp Toxicol 1999;18:154-61.

13. Grankvist K, Stendahl U, Henriksson R. Comparative study of demethoxydaunorubicin with other anthracyclines on generation of oxygen radicals and clonogenic survival of fibroblasts. Pharmacol Toxicol 1989;65:40-4.

14. Hasinoff BB, Hellmann K, Herman EH, Ferrans VJ. Chemical, biological and clinical aspects of dexrazoxane and other bisdioxopiperazines. Curr Med Chem 1998;5:1-28.

15. Hellmann K. Overview and historical development of dexrazoxane. Semin Oncol 1998;25(Suppl 10):48-54.

16. Herman EH, Ferrans VJ. Preclinical animal models of cardiac protection from anthracycline-induced cardiotoxicity. Semin Oncol 1998;25(Suppl 10):15-21.

17. Herman EH, Ferrans VJ. Pre-treatment with ICRF-187 provides long-lasting protection against chronic daunorubicin cardiotoxicity in rabbits. Cancer Chemother Pharmacol 1986;16:102-6.

18. Herman EH, Ferrans VJ. Reduction of chronic doxorubicin cardiotoxicity in dogs by pre-treatment with $( \pm$ )-1,2-bis(3,5-dioxopiperazinyl-1-yl)propane (ICRF187). Cancer Res 1981;41:3436-40.

19. Herman EH, Zhang J, Ferrans VJ. Comparison of the protective effects of desferrioxamine and ICRF-187 against doxorubicin-induced toxicity in spontaneously hypertensive rats. Cancer Chemother Pharmacol 1994;35:93-100.

20. Hochster H, Liebes L, Wadler S, et al. Pharmacokinetics of the cardioprotecto ADR-529 (ICRF-187) in escalating doses combined with fixed-dose doxorubicin. J Natl Cancer Inst 1992;84:1725-30.

21. Jackson JA, Reeves JP, Muntz KH, et al. Evaluation of free radical effects and catecholamine alterations in adriamycin cardiotoxicity. Am J Pathol 1984;117: $140-53$

22. Jones MM, Basinger MA. A hypothesis for the selection of chelate antidotes for toxic metals. Med Hypotheses 1982;9:445-53.

23. Jurga L, Mišurová E, Vančík J. Amelioration of doxorubicin cardiotoxicity by the bispiperazinedione ICRF-187 in women with advanced breast cancer: A preliminary report. Neoplasma 1993;40:259-62.

24. Kamysbaev DK, Utegulov RN, Ospanov KK. Thermodynamics of the complex formation of metals (II) with unithiol in aqueous solution. Russ J Inorg Chem 1993;38:288-90.
25. Keizer HG, Pinedo HM, Schuurhuis GJ, Joenje H. Doxorubicin (adriamycin): A critical review of free radical-dependent mechanisms of cytotoxicity. Pharmac Ther 1990;47:219-31.

26. Lentner C. Heart. Systolic funtion. In: Geigy scientific tables. Heart and circulation. C. Lentner, ed. Basel:Ciba-Geigy Limited, 1990:108.

27. Link G, Tirosh R, Pinson A, Hershko C. Role of iron in the potentiation on anthracycline cardiotoxicity: Identification of heart cell mitochondria as a major site of iron-anthracycline interaction. J Lab Clin Med 1996;127:272-8.

28. Lopez M. Dexrazoxane. Current status and prospectives of cardiotoxicity of chemotherapy. Clin Ter 1999;150:37-49 (abstract).

29. Luo X, Evrovsky Y, Cole D, Trines J, Benson LN, Lehotay DC. Doxorubicin-induced acute changes in cytotoxic aldehydes, antioxidant status and cardiac function in the rat. Biochim Biophys Acta 1997;1360:45-52.

30. Maiorino RM, Weber GL, Aposhian HV. Determination and metabolism of dithiol chelating agents. III. Formation of oxidized metabolites of 2,3-dimercaptopropane-1-sulfonic acid in rabbits. Drug Metab Dispos 1994;16:455-63.

31. Mansour MA, El-Kashef HA, Al-Shabanah OA. Effect of captopril on doxorubicin-induced nephrotoxicity in normal rats. Pharmacol Res 1999;39:233-7.

32. Milner LS, Wei SH, Houser MT. Amelioration of glomerular injury in doxorubicin hydrochloride nephrosis by dimethylthiourea. J Lab Clin Med 1991;118: 427-34.

33. Miwa N, Kanaide H, Meno H, Nakamura M. Adriamycin and altered membrane functions in rat hearts. Br J Exp Path 1986;67:747-55.

34. Seifert CF, Thompson DF, Nesser ME. Dexrazoxane in the prevention of doxorubicin-induced cardiotoxicity. Ann Pharmacother 1994;28:1063-72.

35. Stewart JR, Diamond GL. In vivo renal tubular secretion and metabolism of the disulfide of 2,3-dimercaptopropane-1-sulfonate. Drug Metab Dispos 1988;16: 189-95.

36. Szinicz L, Wiedemann P, Häring H, Weger N. Effects of repeated treatment with sodium 2,3-dimercaptopropane-1-sulfonate in beagle dogs. Arzneim Forsch/Drug Res 1983;33:818-21.

37. Takahashi S, Denvir MA, Harder L, et al. Effects of in vitro and in vivo exposure to doxorubicin (adriamycin) on caffeine-induced $\mathrm{Ca}^{2+}$ release from sarcoplasmic reticulum and contractile protein function in "chemically-skinned" rabbit trabeculae. Jpn J Pharmacol 1998;76:405-13

38. Takahashi Y, Funakoshi T, Shimada H, Kojima S. The utility of chelating agents as antidotes for nephrotoxicity of gold sodium thiomalate in adjuvant-arthritic rats. Toxicology 1995;97:151-7.

39. van Acker SA, Boven E, Kuiper K, et al. Monohydroxyethylrutoside, a dose-dependent cardioprotective agent, does not affect antitumour activity of doxorubicin. Clin Cancer Res 1997;3:1747-54.

40. van Acker SABE, Voest EE, Beems DB, et al. Cardioprotective properties of O( $\beta$-hydroxyethyl)-rutosides in doxorubicin-pretreated BALB/c mice. Cancer Res 1993;53:4603-7.

41. van Vleet JF, Ferrans VJ. Evaluation of vitamin E and selenium protection against chronic adriamycin toxicity in rabbits. Cancer Treat Rep 1980;64:315-7.

42. Venkatesan N, Punithavathi D, Arumugam V. Curcumin prevents adriamycin nephrotoxicity in rats. Br J Pharmacol 2000;129:231-4.

43. von Hoff DD, Layard MW, Basa P et al. Risk factors for doxorubicin-induced congestive heart failure. Ann Intern Med 1979;91:710-7.

44. Weiss G, Loyevsky M, Gordeuk VR. Dexrazoxane (ICRF-187). Gen Pharmacol 1999;32:155-8

45. Wexler LH, Andrich MP, Venzon D et al. Randomized trial of the cardioprotec tive agent ICFR-187 in pediatric sarcoma patients treated with doxorubicin. J Clin Oncol 1996;14:362-72.

46. Xu MF, Tang PL, Qian ZM, Ashraf M. Effects by doxorubicin on the myocardium are mediated by oxygen free radicals. Life Sci 2001;68:889-901.

47. Yin X, Wu H, Chen Y, Kang YJ. Induction of antioxidants by adriamycin in mouse heart. Biochem Pharmacol 1998;56:87-93.

Submitted April 2002.

Accepted May 2002.

Doc. MUDr. Radomír Hrdina, CSc., Charles University in Prague, Faculty of Pharmacy in Hradec Králové, Department of Pharmacology and Toxicology, Heyrovského 1203, 50005 Hradec Králové, Czech Republic. e-mail: hrdina@faf.cuni.cz 